\title{
Exploring Secondary Students' Epistemological Features Depending on the Evaluation Levels of the Group Model on Blood Circulation
}

\author{
Shinyoung Lee $\cdot$ Heui-Baik Kim
}

Published online: 9 August 2013

(C) The Author(s) 2013. This article is published with open access at Springerlink.com

\begin{abstract}
The purpose of this study is to identify the epistemological features and model qualities depending on model evaluation levels and to explore the reasoning process behind high-level evaluation through small group interaction about blood circulation. Nine groups of three to four students in the eighth grade participated in the modeling practice. Their group models, which were represented by discourse and blood circulation diagrams, were analyzed for the development of the framework that informed the model evaluation levels and epistemological features. The model evaluation levels were categorized into levels one to four based on the following evaluation criteria: no evaluation, authoritative sources, superficial criteria, and more comprehensive criteria. The qualities of group models varied with the criteria of model evaluation. While students who used authoritative sources for evaluating the group model appeared to have an absolutist epistemology, students who evaluated according to the superficial criteria and more comprehensive criteria appeared to have an evaluative epistemology. Furthermore, groups with Level four showed a chain reaction of cognitive reasoning during the modeling practice concerning practical epistemology. The findings have implications for science teachers and education researchers who want to understand the context for developing students' practical epistemologies.
\end{abstract}

\section{Introduction}

Cognitive processes in science focus on explaining and predicting the physical world. Scientists construct models to represent and simplify complex phenomena, since it is impossible to study entities as they are (Buty and Mortimer 2008). It is important for students to engage in modeling practices in science education. As they participate in the modeling processes, they develop epistemological understanding about scientific knowledge and knowing by evaluating and modifying the models (Schwarz et al. 2009). In fact, models created by scientists go through similar processes. The empirical and conceptual

\footnotetext{
S. Lee $\cdot$ H.-B. Kim $(\bowtie)$

Department of Biology Education, College of Education, Seoul National University, San 56-1, Sillim 9(gu)-dong, Gwanak-gu, Seoul 151-748, Korea

e-mail: hbkim56@snu.ac.kr
} 
criteria of these models are evaluated on an ongoing basis. If the models cannot meet the criteria, they need to be revised until they can be accepted by peer scientists (Passmore and Stewart 2002). Likewise, students also experience how to generate, evaluate, and modify their models when engaging in modeling activities (Doyle and Ford 1998). However, students have very little chance to be involved in modeling activities, and modeling activities in the science classroom are mainly presented as a way of describing scientific phenomena, rather than constructing scientific knowledge (Krajcik and Merritt 2012; Lehrer and Schauble 2012).

Modeling-based lessons should be provided for students in order to meet the goals of science education, which strives to enable students to experience epistemological understanding. In this regard, small-group modeling activities were designed in our study; students constructed their models and justified them until their models were accepted by other members. Small group interaction can cause cognitive conflicts among students who have different cognitive levels and learning tendencies (Kyza et al. 2011). Through solving cognitive conflicts, students can evaluate their own or others' models and develop their models by modifying them. Therefore, we could expect of students' models to be of higher quality, and modeling practice could be produced by participating in collaborative modeling activities rather than individual modeling activities. Schwarz et al. (2009) viewed modeling as a process of epistemological practices, and the process of students' epistemological practices was considered to be their learning progression.

Students' epistemological beliefs on science can be well presented in the phase of model evaluation (Buty and Mortimer 2008; Oh and Oh 2011). Among the beliefs introduced by Hofer and Pintrich (1997), the certainty of knowledge, source of knowledge, and justification for knowing can be well presented. In terms of certainty of knowledge, modeling evaluation processes either occurred or did not occur depending on students' points of view - that is, according to whether students viewed the models as conveying absolute truth, or as conveying tentative and evolving knowledge. In addition, the quality of models can be determined by whether the source of knowledge is authoritative or rooted in concepts for improving explanation by students. The process of justification for knowing appeared for the purpose of increasing the explanatory power of models. Accordingly, students actively participate in the model construction processes and high-quality models are often produced.

This study aimed to identify the epistemological features that manifested in the model evaluation processes; the model-based lessons about "blood circulation" were designed for this purpose. Since collaborative learning cannot be detected in all small-group learning activities, we chose "blood circulation" as our topic in order to attract voluntary participation from students. Overall thinking skills are needed for students to understand the complex and interactive circulatory system. Exploration of blood circulation involves a wide range of scales that encompass both the visible (heart, veins and arteries) and the invisible (blood cells, oxygen, and carbon dioxide in a capillary) (Buckley 2000). The topic of blood circulation would be appropriate for students to experience the modeling practice systemically. These three lessons have been designed based on group modeling with hands-on activities.

Epistemological understanding on models influences the epistemic process (Windschitl et al. 2008): the higher the level of epistemological understanding (Sins et al. 2009; Windschitl et al. 2008), the higher the level of reasoning and the higher the qualities of the developed models (Cheng and Brown 2010; Schwarz et al. 2009). Hence, this study investigated the epistemological features depending on model evaluation levels in science classrooms and how the reasoning process and the model qualities would be influenced at a 
high level of model evaluation. In this study, we do not intend to match the epistemological features concerning model evaluation to the qualities of the respective models. Rather, we attempt to identify the epistemological features in model evaluation that are likely to influence cognitive processes and model development.

\section{Theoretical Background}

\subsection{Models and Modeling of Blood Circulation}

The model is widely used in many fields of science, including chemistry, physics, earth science, and biology. For example, the principles of chemistry deal with microparticles and their activities and interactions-ideal objects for representations and models (Oversby 2000 , p. 229). Physics turns to models in its need to explain "the way the world works" (Rutherford 2000, p. 254). In the case of earth science, cosmic phenomena or changes in the earth can be described using models. The phenomena of biology also have been explained using models because a greater number of specific laws and concepts exists in biology compared to other branches of science, and living creatures are integrated in a complicated and compositive system that has many interacting parts at the levels of the molecule, cell, organ, and organism (Cartwright 1999, p. 7; Verhoeff et al. 2008).

Blood circulation among biology concepts is not imaginable because of its invisibility. For this reason, both students and teachers experience a strong challenge when attempting to understand blood circulation. ${ }^{1}$ Several studies on the analysis of students' mental models have been carried out in order to understand and avoid misconceptions about blood circulation in the field of science education (Arnaudin and Mintzes 1985; Chi et al. 1994). For example, in a study done by Arnaudin and Mintzes (1985), the authors selected a total of 495 students from the fifth, eighth, and tenth grades as well as college freshmen; the students were asked to explain and describe blood circulation. This process revealed the misconceptions students held regarding the structure and function of both the blood and the heart, circulation patterns, the relationship between circulation and respiration, and also the closed-circulatory system. Their misconceptions about the latter three concepts, which are unapproachable and complicated, were not easily changed. Another study done by Chi et al. (1994) revealed that students had difficulties when they were asked to construct a complete and correct circulation system model regarding the source of oxygen, the purpose of lungs, and the number of loops, and the numbers of circulation cycles. In particular, although some students viewed the circulatory system as a double loop model, they could not explain how each component works. This meant that they were not able to explain the entire system without missing the details, even though they could have a correct model in terms of the flawed mental model. Moreover, Pelaez et al. (2005) claimed that prospective elementary teachers had misconceptions about blood circulation pathways and gas exchange, and their misconceptions could not be easily changed.

Students' misconceptions of blood circulation might be derived from their perception of ontological categories to the phenomena. Chi (2005) viewed the ontological category of blood circulation as a "direct process", and she claimed students' misconceptions of "direct process" might be nonrobust compared to the conception of diffusion, which entails the new effect created by individual components of a process having indirect impact

1 See for instance Arnaudin and Mintzes (1985), Buckley (2000), Chi (2000), Pelaez et al. (2005), Yip (1998) 
on the overall process and was categorized as an "emergent process". In the case of blood circulation, components of the heart have a direct influence on the direction and speed of blood flow, explaining its categorization as a "direct process". However, circulation also can be viewed as an "emergent process" due to the dynamics and its intrinsic randomness (Buckley 2000). That is, blood circulation has a dynamic mechanism because of the gas exchange principle in each organ; the way in which blood is transported to each organ is random; and blood circulation proceeds with the constant interactions among the mechanisms of heart, vessels, and blood. These properties associated with an emergent process can easily cause students' misconceptions about blood circulation.

The findings of these previous studies gave us insights into developing a better way to understand and collect students' models. To minimize and identify students' misconceptions about blood circulation, we involved our students in hands-on activities. The first two lessons were designed to help them understand the basic concepts for modeling overall blood circulation: the structure of the heart, the heart structure for preventing the mixing the oxygenated blood with the deoxygenated blood, the mechanism of one-way blood flow in the heart, and the pumping role of the heart. In this way, students could better understand the heart's structures and functions. The diagram-drawing task, which has been proven to identify students' misconceptions in a previous study (Chi et al. 1994), was arranged as a group activity in the third lesson. Students' individual models and group models could be revealed when they tried to draw a diagram through verbal interaction.

The previous studies on blood circulation models tried to explain what students' models are and why their misconceptions are so robust. However, our study focused on the sociocultural point of view. Núñez-Oveido and his colleagues explored students' modeling processes regarding blood circulation with the help of the teacher from a sociocultural perspective (Núñez-Oveido et al. 2008, pp. 179-183). Unlike Núñez-Oveido and colleagues' study, we aimed to examine the cognitive interactions among students and how they expand in group models, rather than model development under the control of the teacher.

Small-group activities enable students to express various ideas and opinions through their discourses. When students engage in small-group modeling activities, various individual opinions, and evaluations and justifications of these opinions, emerge during this process: ideas are presented and criticized, and students must defend them with evidence (Böttcher and Meisert 2011). These argumentation activities lead to the metacognitive monitoring activities that help each student modify his or her own understanding and the understanding of others (Nelson and Narens 1994). Significantly, small-group modeling activities provide more chances to develop models in a positive way as compared to individual modeling activities. Therefore, we focused on students' epistemological features in terms of justification processes in small-group modeling.

\subsection{Practical Epistemology Revealed During Model Evaluation}

In general, students are asked to engage in scientific inquiry with the goals of learning scientific materials and concepts and of gaining knowledge about the nature of science by taking part in the work that scientists do. In spite of the great emphasis on the importance of scientific inquiry in standard educational documents (NRC 2000), students hardly experience the epistemic features of scientific knowledge in science classroom emphasizing the scientific method (Windschitl et al. 2008). Many authors suggest modeling-based inquiries to overcome the current difficulties in school science (Clement 2000, Gobert and Buckley 2000; Windschitl et al. 2008). Model-based inquiry is a learning strategy that 
helps students construct mental models when they practice a specific learning task, rather than merely using models as instructional materials (Gobert and Pallant 2004).

When students engage in modeling activities, they experience model construction, evaluation, and modification processes that are quite similar to scientists' work. During these processes, their epistemological beliefs could be explored; this is related to practical epistemology (Bell et al. 2010). The hypothesis of practical epistemology is based on the fact that engagement in modeling activities can enhance epistemological knowledge development (Sandoval 2005), and this epistemological knowledge is called metamodeling knowledge (Schwarz and White 2005). Schwarz et al. (2009) proposed a learning progression that reflects the interaction between modeling practices and metamodeling knowledge. This learning progression includes two dimensions-the generative nature of models as tools for explaining and predicting, and the dynamic nature of models as improving with new understanding. One type of learning progression, "the dynamic nature of models as improving with new understanding" (Schwarz et al. 2009, p. 209), reflected students' epistemological features, which were related to understanding the changeable nature of models, evidence of model evaluation such as authority, superficial composition, and explanation to the phenomena, and justification based on evidence. These epistemological features support the ideas of certainty of knowledge related to the nature of knowledge, and sources of knowledge and justification for knowing related to the nature of knowing, which was addressed by Hofer and Pintrich (1997). They tried to emphasize that students should be aware of the fact that knowledge is uncertain, and it can be developed through the interactions with other people concerning the process of knowing.

It is important to note that practical epistemological features of science are well presented during model evaluation process (Buty and Mortimer 2008; Oh and Oh 2011). Students' modeling evaluation processes involve both evaluative epistemology (Kuhn 1991, p. 188) that claims there is no certain knowledge, and model justification processes that justify the models using proper evidence. This indicates that the modeling evaluation process reflects practical epistemology. ${ }^{2}$ In particular, small-group modeling activities enable students who have different knowledge bases to express their own opinions on the social plane. When students faced cognitive conflicts caused by different opinions, they tried to evaluate models using various criteria and justify the models whether they agreed or disagreed with each other concerning what the model should explain about the phenomena, a process that finally resulted in clarity of ideas and concepts (Sandoval and Reiser 2004). This argumentation process not only provides an opportunity to develop epistemic criteria, but could also lead to production of higher-quality models (Böttcher and Meisert 2011). In fact, students' argumentation makes it possible to enhance the quality of reasoning and modify the models by persuading others and justifying their own opinions. In other words, the model evaluation process is a critical phase because students' practical epistemologies can be well presented in this phase.

The present study examined the levels of students' model evaluation during the modeling processes, and further developed a framework that reflects their epistemological features. In addition, the learning progression concerning "the dynamic nature of models as improving with new understanding" (Schwarz et al. 2009, p. 209) was applied to our model evaluation levels. The criterion of evaluation levels focuses on the evidence students used during the evaluation processes. We tried to classify the levels under consideration according to whether they used evidence from authoritative sources and whether they

2 See for instance Buty and Mortimer (2008), Gobert and Pallant (2004), Oh and Oh (2011), Schwarz et al. (2009) 
represented models on the superficial level or on a level that required deeper understanding. Moreover, the epistemological features were inductively concluded by focusing on the reasoning processes students used to justify their opinions and develop their models.

\section{Research Design and Methodology}

\subsection{Participants}

A total of 34 students in the eighth grade from K Girls' middle school of Incheon City, which is one of the metropolitan areas in Korea, participated in this study. They came from middle-class socioeconomic backgrounds. Students worked in groups of three or four (nine groups) and the members for each group were decided on the basis of the students' academic achievement with the aim of having heterogeneity within each group. Group members had remained together during science class from the beginning of the semester so they were quite familiar with each other.

The teacher who participated in this study had an eight-year history of teaching science to secondary students and was in the doctoral program of science education. She had experience in studying small-group learning, especially as concerns argumentation, and had a strong interest in small group activities. She contributed to some aspects of the developed lesson. The teacher worked closely with the researchers to decide how to introduce the concepts of models and modeling and how to apply them to the lessons. Also, she engaged in revising the developed lesson of "blood circulation" with the researchers. The teacher had always supported the students' group activities before conducting this study, and she encouraged the students to actively take part in the group activities in the process of this study.

\subsection{Context}

It was not true that all students experienced the process of science in terms of practical epistemology when they participated in modeling activities in a small group. To help students construct their own models and criticize those of others' by employing evidencebased reasoning skills, we designed three lessons about blood circulation. These three lessons were designed with the following purposes in mind: to organize the lessons systematically, ensure that small group activities were done cooperatively, and ensure that the students understood the causal mechanism of blood circulation.

As described earlier, students can find it difficult to understand the concept of blood circulation because it is invisible and hard to experience (Buckley 2000). Two kinds of strategies were used to minimize students' misconceptions: hands-on activities and diagram drawing. The first and second lessons consisted of hands-on activities so the students could experience practice with an analogous model and the dissection of a pig's heart. Doing this helped students obtain data for the third lesson, develop their representational skills for converting scientific concepts into a diagram or table, and maintain their interest in modeling. Additionally, the students used the drawing method for representing the model of blood circulation. The drawing method is appropriate for enhancing the understanding of scientific knowledge and for identifying the students' modeling performance (Bamburger and Davis 2013).

The goals of three lessons were to identify the structure of the heart, explain the mechanism of one-way blood flow in the heart, and depict blood circulation in the body 


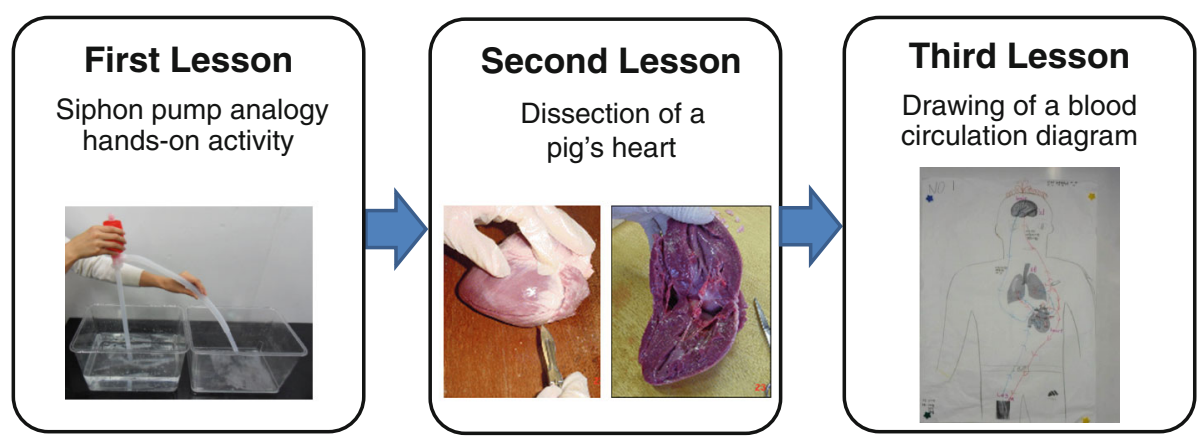

Fig. 1 The implemented lessons of blood circulation

(Fig. 1). The first lesson was about siphon pump activity, which was used for the simulation of heart pumping. In this lesson, the students were requested to do group activities to explain the model in which the water flows in a single direction in the pump. The second lesson was about the anatomization of a pig's heart. The students could observe the heart structure and construct an explanatory model by applying the previous knowledge gained from the first lesson. Students had preconceptions of the heart's structure for preventing mixing of the oxygenated blood with deoxygenated blood, the mechanism of one-way blood flow in the heart, and the pumping role of the heart through these two lessons.

Then, in the last lesson, the students drew a diagram of blood circulation within the group setting. To construct the blood circulation model based on the models obtained in the previous lessons, the students needed overall thinking skills and autonomy. Accordingly, this study was conducted on the basis of the analysis of the modeling practice and the group models of the third lesson. Taking this approach was convenient for identifying the model qualities and modeling performances because the students constructed their models in both verbal and diagrammatic forms.

Because more comprehensive knowledge was required in the third lesson compared to the teacher-centered lecture, the modeling activities were guided by the teacher. The teacher gave each group a piece of paper, pictures of body organs, and red and blue pens, and briefly introduced the small-group activity during the first $10 \mathrm{~min}$. During the following $25 \mathrm{~min}$, the students were requested to do the actual group activities, such as outlining the human body, putting pictures of organs on it, and then marking the structure of the heart. In addition, they also had to link all the organs to the heart. They were given enough time to finish the pathway and then specify the oxygenated and deoxygenated blood and mark how gas exchange occurred in each organ. As a result, students combined several models such as the pulmonary circulation, the systemic circulation, and the gas exchange in lungs and other organs and completed the whole model of blood circulation. Among the nine groups, two of them voluntarily presented their models in front of the class. After that, the rest of the groups could revise their own models by comparing them with the two presenting groups' models in the last $5 \mathrm{~min}$.

The teacher encouraged students to engage in spontaneous model evaluation process using the following four strategies. First, the lessons were not devised with a teachercentered format, but rather with an open-participation format in terms of group modeling. Anderson and colleagues found that the frequency of a sequence of argumentative statements increased with an open-participation format (Anderson et al. 2001). Second, students were given chances to receive some training and guidance in model evaluation during the 
first two lessons. Chances for specific training and help occurred two times during each lesson. Third, the teacher served in a helper role when students became confused concerning the development of models. Among other things, the teacher suggested scaffolding to facilitate the reasoning process anchored to some degree and encouraged students to self-evaluate their models. Fourth, students had the chance to revise other groups' models during the third lesson. Therefore, the lesson implemented in this study encouraged students' autonomy far beyond the traditional teaching and learning approach.

\subsection{Data Collection and Analysis}

Qualitative research was necessary to identify the students' epistemological features in the process of collaborative modeling activities. Since we assumed that sociocultural aspects could have an influence on learning, a survey of not only the preconceptions but also the perceptions about a group activity and group norms were analyzed for all the students. When students represent their mental models as a form of language or physical object, students can identify their ideas clearly. By using this strategy in group modeling, students could construct the collaborative model by considering varying points of view (Windschitl et al. 2008). Gobert (2000) found that drawing diagrams helped students construct the models and promoted revision and representational skills, so the students were asked to draw a blood circulation diagram in this study.

Subsequently, we analyzed the students' blood circulation diagrams to have a better understanding of their models. However, the diagrams alone were insufficient to enable us to understand the students' reasoning processes and the intermediate models they created. In this regard, as well as for the diagrams, we employed videos that included the students' discourses and behaviors to examine the development of the intermediate models. In other words, we analyzed two kinds of models, one in the form of our study diagrams and the other as an explanatory model represented in the discourse.

\subsection{Framework for the Process of Model Development}

The mode for the process of model development used by Clement was modified to analyze the students' interactions and the process of model development (Clement 2008, pp. 11-22). The process of development was examined by analyzing the utterances of both the student leader and non-leaders. Leaders in each group were identified based on the findings of Bianchini (1997) that students who actively participated in group discourse contributed to the group learning and had a higher position than other students within a group. Within each group, the academic achievements of the leaders were higher than those of the other students. They presented their ideas actively, gave scaffolding to others, and encouraged other students to participate in group discussion.

Figure 2 shows the framework for the process of model development. The utterances of the leader students, the teacher, and non-leader students are presented respectively in three different sections. As can be seen, students' utterances represent outward the line, while some omitted parts and meaningful behaviors are depicted in parentheses by the researchers. The rounded squares in the middle part represent the models, and are placed in order of development, i.e., M0, M1, M2, M3, and M4. The small squares show the order of the utterances. For example, A-5, in the small square, represents the fifth utterance of student A. Moreover, the thin arrows represent the students' utterances and inferring models, while the thick arrows indicate the process of model development. A-1, D-2, and A-3 were contributed to build the initial model (M0), which facilitated the sequences such 


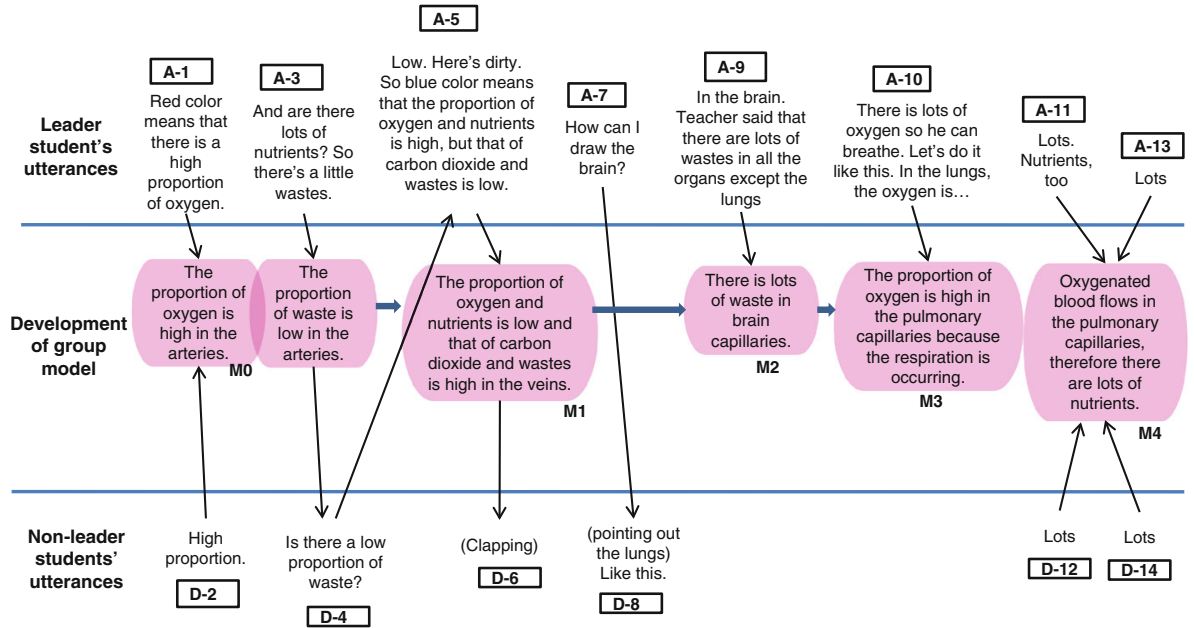

Fig. 2 Framework for the process of model development

as D-4 and A-5 and developed into the intermediate model (M1). Use of this framework greatly facilitated examination of the generation, evaluation, and modification process of the models and also of the utterances and the students who contributed to the model development.

\subsection{Target Model for the Blood Circulation}

Two kinds of target models of the blood circulation were identified as representing the key idea (Figs. 3, 4). The model qualities were examined in terms of the explanatory nature of the models. Figure 3 clearly shows the blood circulation pathways and was used when analyzing the students' diagrams. The students needed to understand that the whole structure of the heart, such as right/left atriums and right/left ventricles, and the terms related to the vessels, such as pulmonary veins/arteries, should be correctly marked in the right places. Also, they needed to know where the organs and muscles were placed and correctly connect them to the heart. The blood circulation pathways can be mainly divided into two parts: pulmonary circulation and systemic circulation. While pulmonary circulation is the pathway connecting the heart and lungs, systemic circulation indicates the pathway between the heart and each organ and muscle. Oxygenated blood should be marked as red on the blood vessels that carry blood outward from the lungs to the heart and from the heart to each organ and muscle. On the other hand, deoxygenated blood, which carries blood from the heart to the lungs as well as conveys blood outward from each organ and muscle to the heart, should be marked as blue. Moreover, students were asked to explain how gas exchange occurred in the lungs, in each organ, and in muscles.

Figure 4 is the visualization of the target model introduced in Buckley and Boulter's study (Buckley and Boulter 1996, p. 128). This model has been used for comparing the students' explanatory models represented in this discourse, which are focused on the various mechanisms pertinent to blood circulation, such as the heart's role of pumping and gas exchanges in the lungs and other organs. The structure of the objects is placed in the boxes; the explanations above the arrows represent the actions, and the bigger square boxes show the mechanism. 
Fig. 3 Target model represented in drawing of the blood circulation

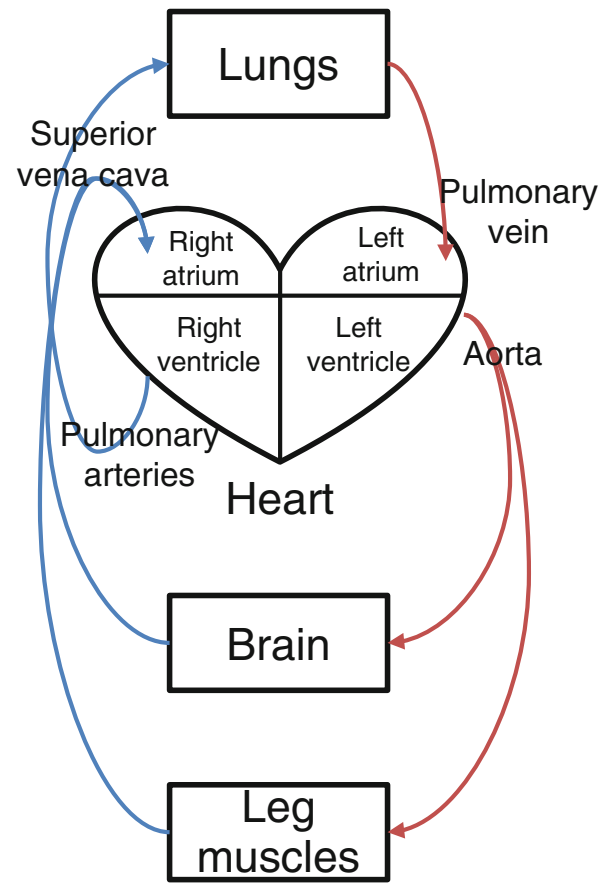

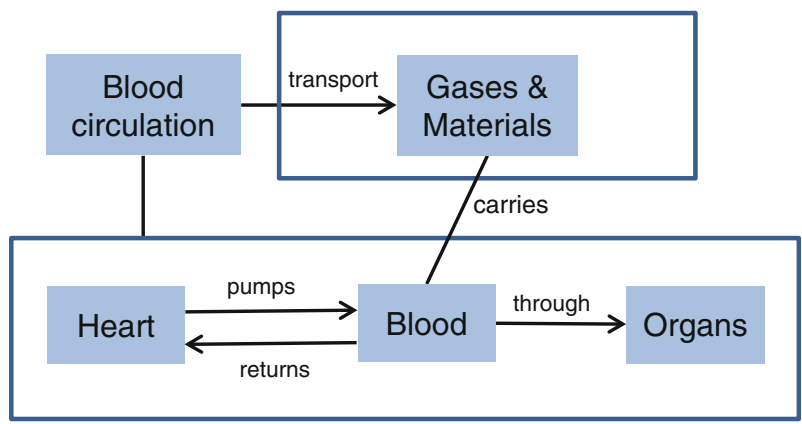

Fig. 4 Target model represented in discourse

\subsection{Framework for Levels of Epistemological Features Depending on the Model Evaluation}

A framework concerning students' epistemologies has been developed by analyzing modeling processes and metamodeling (see Table 1). This framework was based on one of learning progression dimensions, the "models as changeable entities" identified by Schwarz and his colleagues (Schwarz et al. 2009, p. 647). This notion focuses on how students understand the changes in their models and compare and evaluate their models in order to communicate with each other and better explain scientific phenomena using evidence. Hence, our focus also rests in the model evaluation processes, since model dynamics can be well reflected in this phase. On the other hand, epistemological features were concluded 
Table 1 Levels of model evaluation and epistemological features

\begin{tabular}{|c|c|c|}
\hline Level & Performance & Epistemological features \\
\hline 1 & Students do not evaluate the models & $\begin{array}{l}\text { Students neither justify the models nor modify } \\
\text { the models by applying scientific reasoning }\end{array}$ \\
\hline 2 & $\begin{array}{l}\text { Students revise models based on information } \\
\text { from authority such as a teacher, a textbook, a } \\
\text { peer and so on }\end{array}$ & $\begin{array}{l}\text { Students justify the models not through the use of } \\
\text { scientific reasoning, but through use of } \\
\text { authoritative sources that they regard as } \\
\text { possessing the absolute truth }\end{array}$ \\
\hline 3 & $\begin{array}{l}\text { Students evaluate the models using superficial } \\
\text { criteria such as aesthetics and features and } \\
\text { terminology that are the superficial components } \\
\text { of the models related to communication }\end{array}$ & $\begin{array}{l}\text { Students justify the model with evaluative } \\
\text { epistemology, but their justifications are based } \\
\text { on simple comparison of the superficial aspects } \\
\text { of the model. Thus, their models become more } \\
\text { elaborate on the superficial level }\end{array}$ \\
\hline 4 & $\begin{array}{l}\text { Students evaluate the models using more } \\
\text { comprehensive criteria such as processes and } \\
\text { mechanism that relate to the explanatory nature } \\
\text { of the models about phenomena }\end{array}$ & $\begin{array}{l}\text { Even if cognitive conflicts exist among group } \\
\text { members, they solve problems by justifying } \\
\text { their own claims using more comprehensive } \\
\text { criteria. This process leads to the chain reaction } \\
\text { of cognitive reasoning with the evidence. They } \\
\text { seem to have evaluative epistemology. The } \\
\text { group model ultimately becomes more } \\
\text { sophisticated because of the justification that } \\
\text { occurs during the process of reasoning. They } \\
\text { seem to understand the explanatory nature of } \\
\text { models }\end{array}$ \\
\hline
\end{tabular}

inductively by analyzing the reasoning process that emerged during the process of model evaluation.

As shown in Table 1, four evaluation levels are presented according to the students' performances. Their performances are related to their understanding of whether or not the models are changeable and to the source of evidence, such as authoritative sources, the superficial component of models, and the explanatory nature of models. Level 1 indicates that students see models as unchangeable and that they do not justify the models using scientific reasoning. At Level 2, they consider that models can be changeable, but their criterion of model evaluation is based on authoritative sources. Model justification is not based on scientific reasoning but authoritative knowledge that they believe to be absolute knowledge. Students' performances change at Level 3, at which the superficial component of models is considered to be the optimal model evaluation criterion. Yet, with Level 3 students only attempt to use superficial criteria such as aesthetics and features and terminology. Despite the superficial level of the criteria, their attempt to justify the models can be seen; as a result, the models are only modified on the superficial level. At Level 4, students evaluate the model using more comprehensive criteria such as processes and mechanism. With Level 4 in particular, cognitive conflicts among group members surface and influence performance of the group, but some chain reactions involving cognitive reasoning emerge and the models become more sophisticated. This is because the evaluation criteria require higher level understanding of topics related to how scientific phenomena occur. The evaluation criteria for model explanation follow Nelson and Davis (2012)'s definition (see Table 2), which emphasizes aesthetics and features, terminology, processes, and mechanism.

To ensure the reliability of the results, the researchers carefully proceeded through every step from framework development to data coding. After developing the framework, 
Table 2 Coding scheme for model evaluation criteria (Nelson and Davis 2012, p. 1940)

\begin{tabular}{ll}
\hline Code & Explanation \\
\hline $\begin{array}{c}\text { Aesthetics and } \\
\text { features }\end{array}$ & $\begin{array}{c}\text { Students comment on model criteria/components: neatness, artistic quality, arrows, } \\
\text { labels, key, zoom view title, and internal consistency } \\
\begin{array}{c}\text { Mechanism or } \\
\text { process }\end{array} \\
\text { Students mention change over time, process, mechanism, causality, and/or variables or } \\
\text { influential factors that govern the phenomenon }\end{array}$ \\
\hline
\end{tabular}

each researcher independently conducted data coding in terms of model evaluation and modeling practice levels. If any pair or group of researchers found differences in data coding, they tried to achieve a consensus through discussion.

\section{Results and Discussion}

In this section, we present the performances according to the model evaluation levels and the epistemological features found in the science classroom. The model evaluation levels were categorized by levels one through four, based on the evaluation criteria as well as on an understanding of the changeable nature of models and the explanatory nature of the model. The modeling performances influenced model quality. When more comprehensive criteria were used during model evaluation, cognitive reasoning chains were present during the modeling process.

\subsection{Epistemological Features and Model Quality Depending on the Different Levels of Model Evaluation}

\section{The phase without model evaluation}

The process of justifying models was not expressed by students in the first level, because they did not evaluate and rebut the model. It may be construed that students were demonstrating an absolutist epistemology, but this is not accurate; rather, in this phase students might have thought it unnecessary to evaluate the model. Concepts in blood circulation that were modeled included pulmonary circulation, systemic circulation, gas exchange in the lungs and other organs, one-way blood flow in the heart, and so forth. These concepts had sub-concepts with variable ontological categories, and students had different understandings depending on these conceptual variations.

The ontological category of blood circulation is an emergent process, because the means of delivering blood to each organ happens randomly, and the elements of the heart, blood vessels, and blood interact with each other, triggering the mechanism (Chi 2005). By just focusing on the single pathway of pulmonary circulation, however, students would understand pulmonary circulation better than systemic circulation. This is because pulmonary circulation has a single pathway, and the circulation system has multiple pathways. For this reason, we assumed that it would be easier for students to represent the pulmonary circulation model, and modeling of pulmonary circulation would be found in all cases at Level 1 . However, there were only two cases out of twenty-seven modeling processes that led to Level 1. This is because the students in our sample actively participated more in the discourse and modeling practice than did other school students. 
Figure 5 sets out the discourse that students in Group 8 used when discussing pulmonary circulation. A leader in the group completed the pathway of pulmonary circulation that connects the organs. Although the leader generated an incomplete model that lacked the transportation of gases and the gas exchange mechanism, there was no model evaluation or modification. Students focused on visualizing the structure and the pathway of pulmonary circulation, which is an obvious phenomenon at this level. In contrast, the function and mechanism of blood circulation, which requires deeper thinking to understand, had not yet been taken into consideration. As a result, the group's model of pulmonary circulation lacked the mechanism that blood uses to transport gases and materials. A detailed model of Group 8 is shown in Fig. 6.

2. The phase of model evaluation using authoritative sources

Students at Level 2 were likely to evaluate models using evidence from authoritative sources such as teachers, high achievers, textbooks, and so forth. In fact, students evaluated

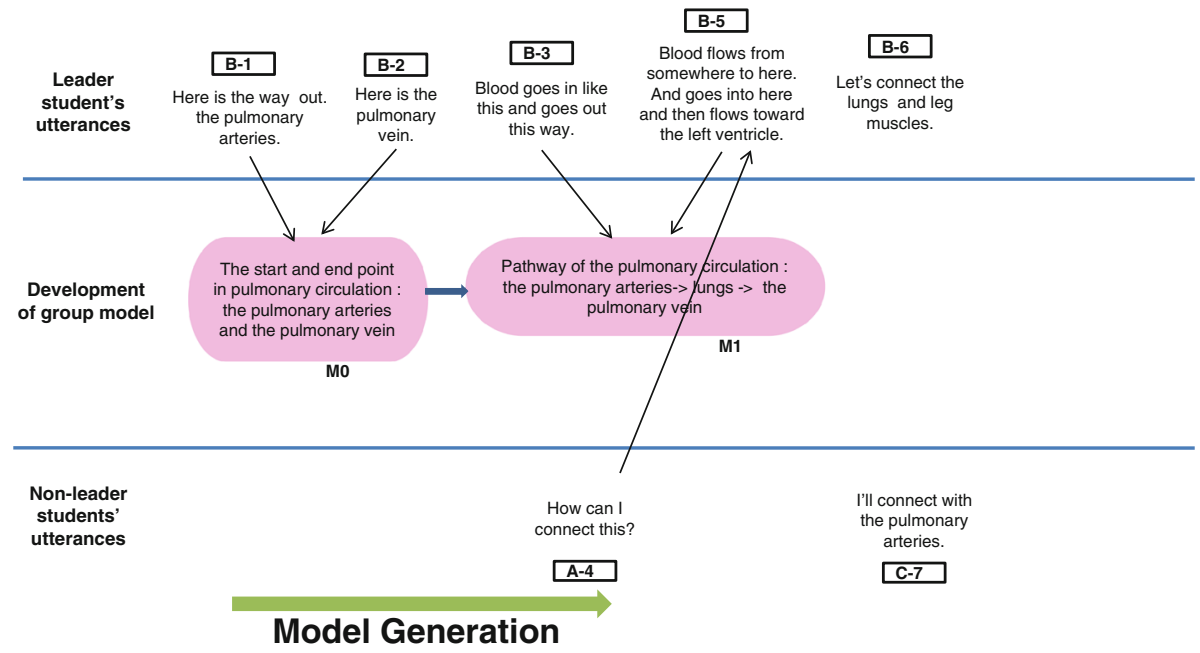

Fig. 5 Discourse during Group 8's model development of a pulmonary circulation

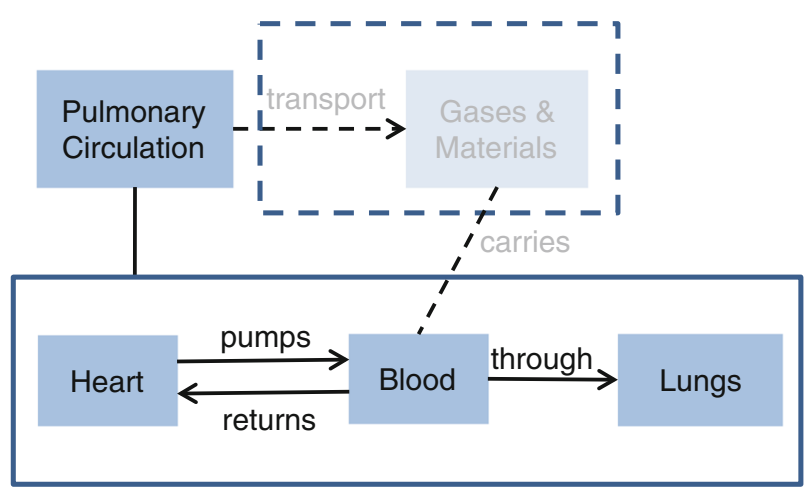

Fig. 6 Group 8's discursive model of pulmonary circulation 
the models constructed in their groups because they knew their models were not perfect. However, deeper consideration about functions and mechanisms of blood circulation did not emerge at this stage. Students did not consider the explanatory nature of models as evaluation criteria. They seemed to have an absolutist epistemology as they perceived the changeable nature of models, yet regarded the authoritative sources as the absolute criteria. Absolutists perceive knowledge as absolute and emphasize authority as evidence of knowing (Kuhn 1991, p. 173). Students in this case wrongly adopted the authoritative information, and non-leader students did not play the role of critical listener. As a result, misconceptions in the group model were not revised.

In Group 4's case, lecture notes hindered the revision of the systemic circulation diagram, which is used as a criterion of model evaluation. As can be seen in Fig. 7, Student A tried to evaluate the blood circulation diagram by comparing it with diagrams in the textbook (A-6). However, she changed her mind when Student B showed her the lecture notes (B-7), and she used the notes as an evaluation criterion instead of the textbook. Later she repeated the quotes from the lecture notes- "Blood flows via the whole body and goes to the superior vena cava" (A-9) — and ceased further revision of the concept.

Taking a closer look at Group 4's explanatory model represented in discourse (Fig. 7), its systemic circulation starts from the left ventricle and goes to the pulmonary vein. In this sense, the students perceived the principle of blood circulation as pressure, as it is clear they believed the heart is the power source of blood circulation. However, in the blood circulation diagram (Fig. 8), systemic circulation is represented as a linear concept, meaning that the blood starts from the lungs and is then transported into the arm muscles, from which it then flows into the leg muscles and brain before returning to the heart in a stepwise fashion. As can be seen from the inconsistency between the model described in discourse and the model represented in the diagram, students did not understand the mechanism by which the heart powers the circulation of the blood. It is worth reflecting on the fact that students were given somewhat fragmentary knowledge concerning the left ventricle as the starting point of the circulatory system.

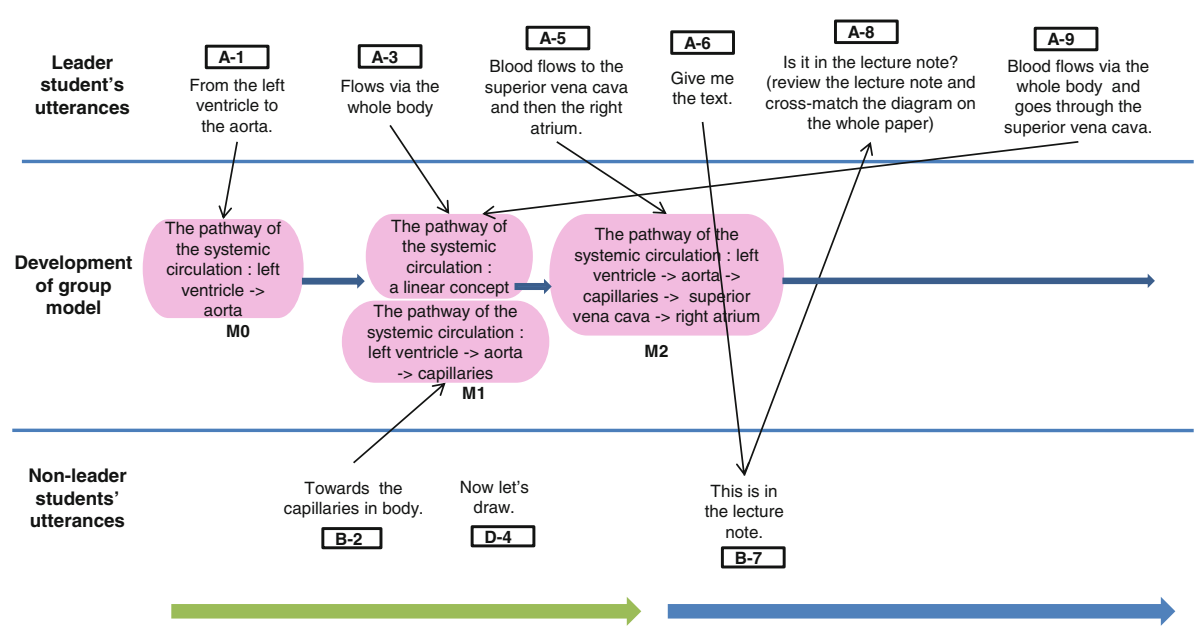

Model Generation

Model Evaluation

Fig. 7 Discourse during Group 4's development of the model for systemic circulation 

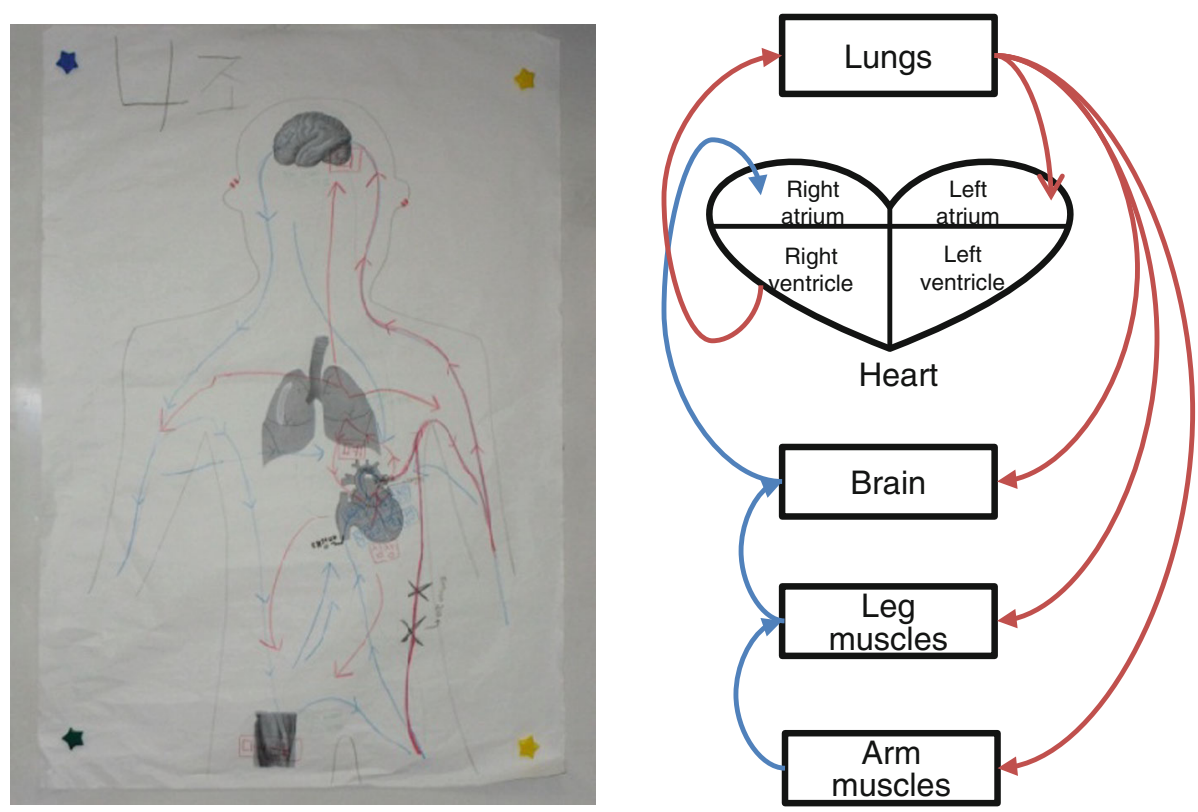

Fig. 8 Group 4's diagram model of systemic circulation

The diagram model of Group 4 had two kinds of misconceptions (Fig. 8). The first misconception was that oxygenated blood flows directly from the lungs to each organ without passing through the heart. The other misconception was the linear concept, whereby the blood starts from the heart and finally flows back to the heart after passing through each organ. In this case, students had an incorrect understanding of systemic circulation. This misunderstanding resulted from the simpler explanation written in the lecture notes. Student A-3 and A-5 wrote, "Blood flows via the whole body and goes to the superior vena cava," when he was listening to the teacher's instructions. In fact, the original and correct concept was "Blood flows outward from the heart to each organ through the distributed pathways and flows back to the heart again." The utterance of Student A-3, "flows via the whole body," could be evidence of how this misconception occurred. This is consistent with the finding of Arnaudin and Mintzes (1985) that misconceptions originate from teachers' instructional methods.

The passive participation of those students not playing leadership roles could be another cause of the error that surfaced. Their passive attitude toward group discussion might mean that they agreed with the student leaders' opinions. Students in Group 4 did not demonstrate behavior associated with critical listeners. However, it is not true that only the student leader was involved in model construction, as both Students B and D had participated in the modeling practice, and Student D expressed her opinion. Unfortunately, they were not involved in the meaningful cognitive process. Indeed, none of them expressed a different opinion when Student A evaluated the model according to the authoritative source, the lecture notes.

\section{The phase of model evaluation using superficial criteria}

Students tended to evaluate the superficial model components by presenting the evaluative epistemology. People who use evaluative epistemology consider the adequacy of 
multiple views and understand the concept of comparing or evaluating variable points of view (Kuhn 1991, p. 188). But the students used superficial criteria for evaluating the appropriateness of the model, such as aesthetics and features and terminology which were model components. The superficial criteria could be important evaluation criteria because it might help students communicate ideas with others and make others understand models (Bamburger and Davis 2013). However, revisions to the group model were based on aesthetic aspects as opposed to a mechanistic explanation of the phenomena. Students seemed to consider the role of model as description of phenomena at Level 3.

In an example of Level 3 understanding, students evaluated the model using a superficial criterion, aesthetics. As shown in Fig. 9, all students in Group 6 actively participated in the modeling process by questioning the figure of a hand. Their questions were related to the model evaluation, and aesthetics were employed as a criterion. Student A explained her intention of expressing the figure of an open hand to justify her own model (A-15), which showed an epistemological feature that did not justify her model based on the function or the mechanism of blood circulation. Taking a look at the revision process of systemic circulation of the hand, Student $\mathrm{C}$ also focused on the aesthetic aspects, asserting that there should be fingers in the diagram (C-16). As a result, the blood vessels in the hand and the leg in the diagram are like an open blood-vascular system. Though this group did not make a major mistake, such as the linear concept mistakes made by Group 4, the open bloodvascular system error was represented in their diagram (see Fig. 10).

\subsection{What Leads to the Highest-Level Model Evaluation Process?}

Only three of twenty-seven cases of modeling were found that represented Level 4 of model evaluation. Students at this level showed evaluative epistemology through the use of more comprehensive criteria such as processes and mechanism to evaluate the explanatory nature of their models. They understood the role of model as explanation of phenomena which might be complex and invisible. According to our analysis, there was cognitive conflict in the process of monitoring. This cognitive conflict occurred when students asked

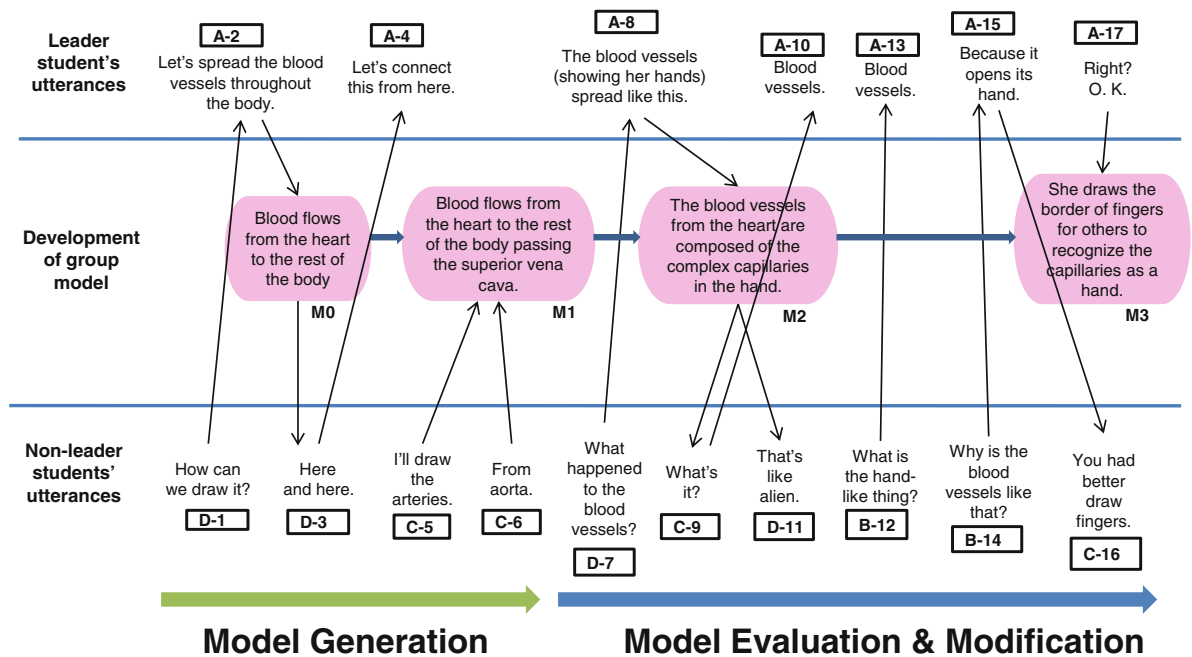

Fig. 9 Discourse during Group 6's model development of systemic circulation 
Fig. 10 Group 6's diagram model of blood circulation

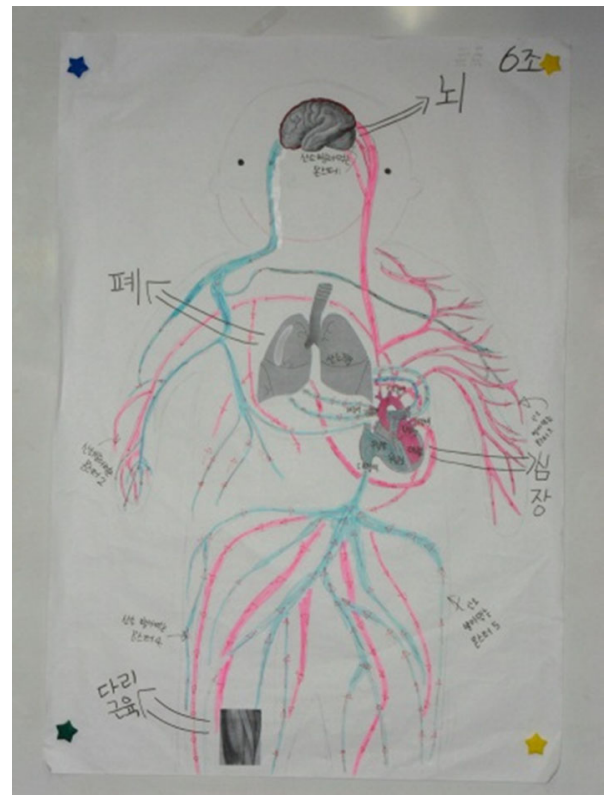

questions to check their own understanding, or to revise incorrect concepts by checking the understanding of others. This type of checking and verification of understanding is a metacognitive activity.

Metacognition refers to the skills that enable learners to understand and monitor their cognitive processes (Schraw et al. 2006). Since small-group modeling activity involves collaboration between several people to construct knowledge, metacognition occurs not only in an individual learner, but also among individuals. Throughout this activity, learners can identify the constructed models using metacognitive skills. Accordingly, the model also undergoes a process of evaluation, revision, and elaboration in terms of a chain of cognitive processes. At Level 4, students could engage in authentic modeling process, which enabled to give students chances to reason scientifically concerning practical epistemology (Svoboda and Passmore 2013). These findings reinforce previous studies describing how conflict among different views affects genuine interaction and can impede revision and development of an original theory (Hofer and Pintrich 1997).

\subsection{Checking Self-Understanding: Raising Questions}

From the perspective of conceptual change, cognitive conflict refers to the inner conflict that occurs when learners try to transform their "naïve knowledge" into scientific knowledge in order to learn a new concept (Dreyfus et al. 1990, p. 555). When students use the Socratic Method to identify their preconceptions and become aware of how they differ from other views, cognitive conflict may be triggered (Champagne et al. 1983). It should be noted that, during the modeling activity, there was a finding of cognitive conflict among those at Level 4.

As shown in Fig. 11, a student raised a question in order to monitor her own understanding, when she noticed that another student's mental model was different from her own prior knowledge. Questions asked of students have an effect on self-reflection and self- 


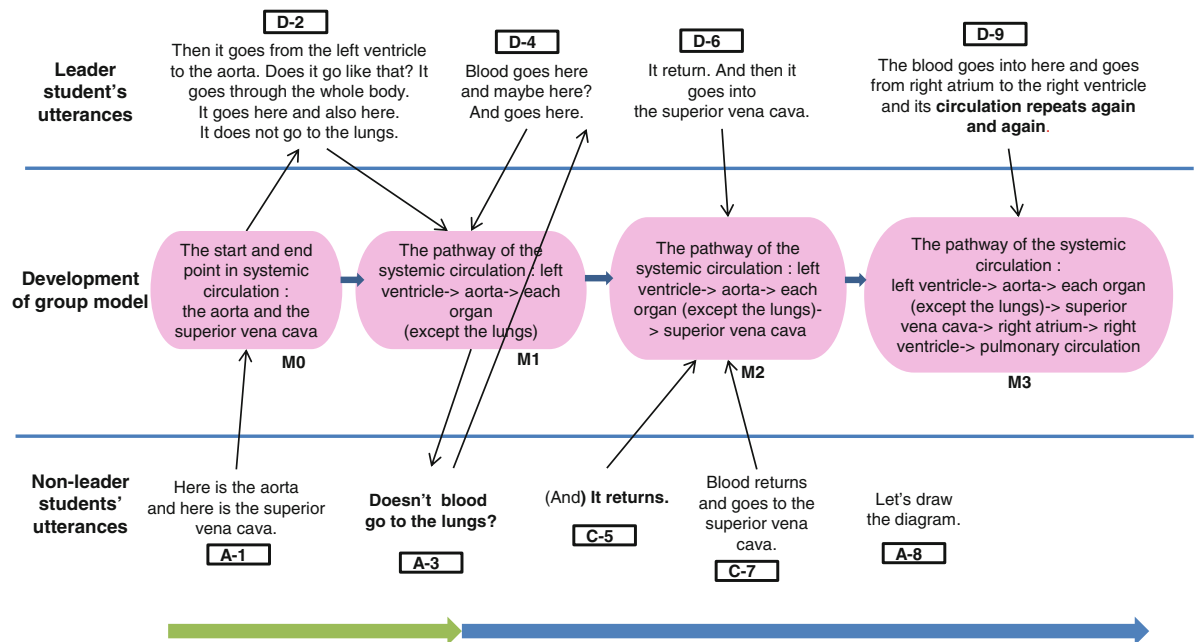

Model Generation

Model Evaluation \& Modification

Fig. 11 Discourse during Group 1's model development of systemic circulation

monitoring skills (Chin and Osborne 2008). In this case, cognitive conflict showed up on the social plane, and generated a series of cognitive processes such as monitoring by the student of her own understanding, along with the generation, justification, evaluation, and modification of the model. As a result, the group model was revised through the aspect of process: that is, having more comprehension.

Taking Group 1's experience, for example, both Students A and D were constructing the systemic circulation model (A-1, D-2). Student D said blood flows from the aorta to each organ following the distributed pathways, and it does not go into the lungs (D-2). Then Student A asked, "Doesn't blood go to the lungs?" (A-3). This question expressed the cognitive conflict potentially being experienced in this small group. Because Student A requested the justification of Students D's statement (D-2) which was different from her own idea. The question also served as a mechanism for solving the cognitive conflict, because asking the question required an answer as to whether or not blood goes into the lungs. In addition, this was an example of model evaluation using the criteria of process of the phenomenon, because Students A and D articulated their understanding as an expressed model to help their thinking and develop group consensus (Nelson and Davis 2012).

At the same time, Student D could identify the concept of distributed pathways and check the modeling process when she answered this question (D-4). At the same time, Student D pointed out the pathway for justifying her own claim. The utterance made by student D (D-4) in response led to a subsequent model evaluation. For example, Student C evaluated Student D's utterance, pointing out that some pathway of circulation was missing in D's utterance and modifying it by referring to the movement of the blood from each organ before returning to the heart (C-5). Later, she emphasized the point again, that blood returns to the heart after going through each organ (C-7). Her modification contributed to the clear depiction of blood circulation in the group's model. Moreover, Student D's rephrasing of the issue emphasized the round trip idea of blood flowing in a continuous circle from the heart to the body (D-9). She did not just arrange the blood circulation pathways; instead, she focused on the repetitive process of circulation, which extended the 
meaning of the model of systemic circulation. She acknowledged and shared the meaning that blood circulation was categorized as an emergent process through a group discussion. In this regard, the questioning that occurred during the process of constructing the model led to a cascade of generative activity. It not only solved the cognitive conflict but also promoted a chain of cognitive processes in terms of authentic modeling process that contributed to the elaboration of the model (Chin and Osborne 2008).

Along with the diagram of Group 1, the explanatory model represented in the discourse (Fig. 12) provides an accurate representation of systemic circulation. When they drew the diagram, they first figured out the starting point and the finishing point of the blood circulation system (the heart) and then arranged the structures as well as the pathways. We inferred from this that the students understood that the heart works as a pump, even though there was no explicit statement to indicate this. Actually, this assumption is supported by the fact that their blood circulation diagram reflects their clear understanding of the scientific concept of the systemic circulation distributed pathway. This finding shows that they evaluated the model by asking a question that request the explanation of a process in terms of sense-making. An epistemological feature should also be noted, i.e., students generated the systemic circulation using discourse and showed scientific reasoning process through justifying their own claims during a model-based inquiry, which cannot be represented by the two-dimensional diagram.

\subsection{Monitoring Others' Understanding: Emergence After Expression of an Incorrect Concept}

Cognitive conflict among group members occurred when someone tried to construct the model with an incorrect concept, and it was solved with the help of peer monitoring. This behavior engages learners in a chain of cognitive processes. Students evaluated the explanatory nature of models using more-comprehensive criteria such as a process or a mechanism. Accordingly, they justified their claim with their own reasoning. Students were elaborating on the model and connecting it to their knowledge, which could either have been gained from the task at hand or have been held beforehand (Sins et al. 2009).

An episode selected from Group 6 illustrates this case (see Fig. 13). When Student D tried to use an incorrect concept to construct the model (D-2), Student C immediately pointed out the mistake and revised it (C-3). This helped Student C externalize her own model in terms of explanation of the pulmonary arteries (King 1994). She evaluated the
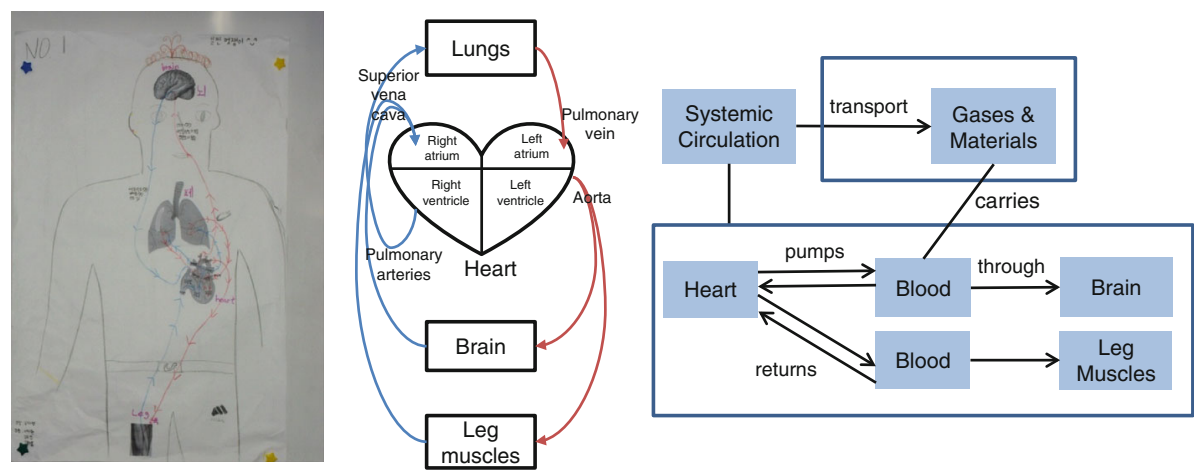

Fig. 12 Group 1's diagram model of blood circulation and discursive model of systemic circulation 


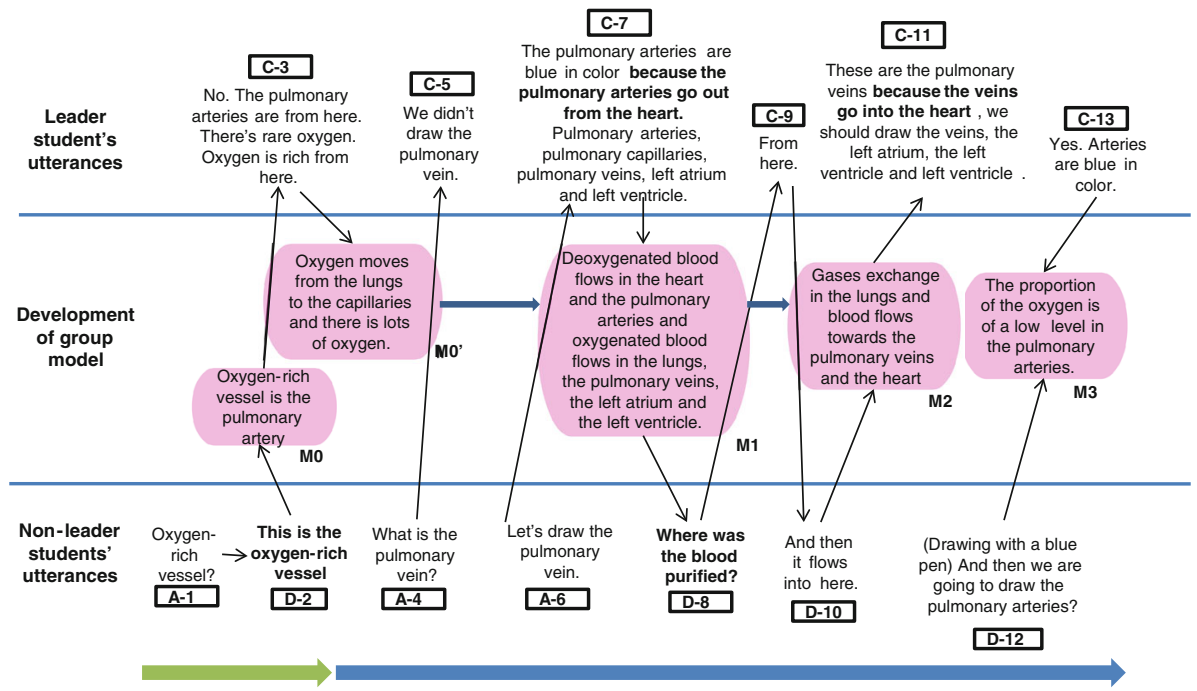

Model Generation

Model Evaluation \& Modification

Fig. 13 Discourse during Group 6's model development of pulmonary circulation and gas exchange

model using the criterion of the model's structure and modified the model to show that the pulmonary artery is an oxygen-poor vessel. In addition to the revision, she also showed the simple structure of argumentation by suggesting the reason that warranted the marking of a blue line on the pulmonary arteries (see C-7). Through her explanation, Student D was able to replace a previously held incorrect concept with the correct concept, and she could then participate in the modeling actively. This extended model caused Student D to begin selfmonitoring, which was expressed as questioning (see D-8). Her question concerned the mechanism of gas exchange in the lungs, a new concept that had not been mentioned in Student C's statement. Student D was then able to evaluate the existing model.

As a result, cognitive collaboration was taking place in the modeling process. In other words, Student C's explanatory model helped Student D's learning, while Student D's questions gave Student $C$ the clue that enabled her to elaborate on the model. In a related study, "bi-directional scaffolding" within group peers was found (Goos et al. 2002, p. 196). In light of this, we believe there was interactive scaffolding taking place between Students C and D. At first, their model about circulation was incomplete; however, it became complete as they emphasized two facts: the pulmonary vein as an oxygen-rich vessel and the mechanism of gas exchange in the lungs. As a result, they could evaluate their model with more-comprehensive criteria. Student D's utterance- "purified"- (see D-8) is actually a spontaneous term, not a scientific term, but it led the discussion to gas exchange, which is an important mechanism in pulmonary circulation. This discourse is an example of how one student provides scaffolding for another student, which helps the student to know the mechanism within her the zone of proximal development (ZPD). This is because they achieved two goals, revising the wrong concept and sharing the revised concept.

The explanatory model represented in discourse, on the social plane, was internalized by individual students, which is to say that the group model became shared knowledge among group members. The fact that students showed confidence in their understanding of blood 

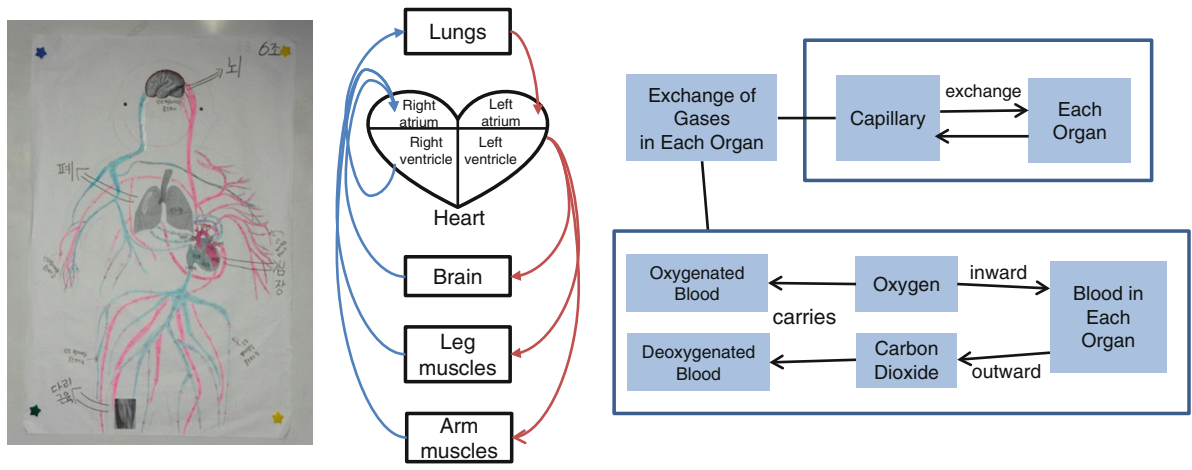

Fig. 14 Group 6's diagram model of blood circulation and discursive model of exchange of gases

circulation in the questionnaire administered at the end of the study could support this internalization. Student D's participation in the cognitive process might also have emphasized the distributed knowledge (D-10). In other words, the question raised by Student D (D-8) brought attention to gas exchange. As can be seen in C-11, Student C gave a clear explanation about gas exchange and also clarified the position of pulmonary veins, constructing the model in the process of justifying her opinions (see C-11). They represented not only the structure and the pathway but also the reason why the pulmonary arteries and the pulmonary veins existed as they did with their own knowledge. This demonstrated the epistemological process of knowing.

The diagram made by Group 6 represents the result of cognitive collaboration. Only the structures and pathways can be identified in Group 6's diagram (see Fig. 14). However, their discourse revealed that they had generated this model perfectly, including its mechanism, through cognitive interactions among themselves.

\section{Conclusions and Implications}

This study aimed to identify the epistemological features of the group modeling process about blood circulation, which is an emergent process based on Chi's (2005) ontological category. Our assumption is that students' epistemological ideas can be expressed when they participate in the group modeling situation of generating and evaluating knowledge (Sandoval 2005). Model evaluation levels were categorized based on several criteria and on the levels' epistemological features. The chain of cognitive reasoning was found in the context of a high level of model evaluation. These findings have implications for the goal of science education in terms of developing students' epistemologies.

The first purpose of the study was to explore epistemological features and model qualities depending on the model evaluation levels. The model evaluation levels were defined as Levels 1-4 based on the evaluation criteria; the higher levels reflected a greater depth of critical thought and metacognitive monitoring concerning the changeable nature of models and the explanatory nature of the model. Students that expressed an absolutist view regarded authoritative sources as conveying absolute knowledge; conversely, students displaying an evaluative epistemology used evidential reasoning to justify their own claims and to criticize the claims of others. The models in Levels 1 through 3 were not able to represent the emergent process of blood circulation, and some models had misconceptions, 
such as the lungs serving as the pumping origin of blood and the linear concept of blood circulation.

Level 1 of the model evaluation mainly occurred when students engaged in modeling pulmonary circulation. This was because students could not have thought of the necessity of change; in other words, it was shown that the evaluation performance depends on the ontological categories of models. At Level 1, the target model for pulmonary circulation had a single pathway through which circulation occurred, which is much simpler than systemic circulation with multiple pathways. This simplicity led students to recognize the pulmonary circulation as a direct process and to easily construct the model by focusing only on this single pathway; due to this ease, students did not evaluate and modify the model.

At Level 2, students recognized the necessity of revising the model; the evaluation criteria were authoritative sources. As students justified their models and evidences through comparison with authoritative sources rather than their own reasoning, they perceived the sources as being absolutely true; that is, in terms of an absolutist epistemology. For this model, the misconception existed in the content of the teacher's lecture, which was written incorrectly; this served as a criterion for evaluating the model.

At Level 3, students demonstrated evaluative epistemology by using their own reasoning to evaluate the model. However, they reasoned by comparing the model with superficial criteria. As a result, only the aesthetic features of the models were further developed beyond the epistemology in Level 1 and Level 2. Students did not understand the goal of model as explaining the phenomena.

The second purpose of the study was to identify the epistemological features in terms of the cognitive reasoning process for understanding the context of Level 4 model evaluation. At Level 4, students evaluated the explanatory nature of the model in terms of the processes and the mechanisms of the phenomena depicted. This evaluation was based on the epistemological belief of knowing that the model constructed within a group should be evaluated for further development and alteration. Cognitive conflict was the main cause of these features, and it was triggered when students attempted to use metacognitive monitoring to examine their own or others' understanding. Students actively participated in cognitive processes in order to solve cognitive conflict among group members; they also evaluated and justified the explanatory nature of models with more comprehensive criteria, such as whether the models accurately depicted mechanisms and processes with respect to the circulatory system. The model for circulation was then elaborated on.

From a sociocultural perspective, knowledge is constructed in a social plane and human mental processes are context-dependent (Wertsch 1991). Learning effects can be enhanced by engaging learners in group activities. Indeed, learning that reflected a sociocultural perspective was clearly shown at Level 4 of the model evaluation. When students were requested to engage in group modeling, they shared their own mental models with group members, allowing each individual's degree of understanding to be identified as the groups worked together. Interactive scaffoldings between group members were presented accordingly. This process induced students to develop the explanation of their models; the ideal practical epistemology was well-expressed and showed that cognitive collaboration among students occurs during mutually supportive engagement in a group modeling activity.

One important finding of our study is that the number of Level 4 cases was highly limited. Most cases were at Level 2 and Level 3. The possibility is that students were not provided explicit criteria for model evaluation though they were given chances to receive some training and guidance in model evaluation during the first two lessons. However, this 
indicates that a lack of in-depth evaluation exists with respect to models that provide explanations for mechanisms or processes of scientific phenomena, even though students have an epistemological awareness that the model should be validated. Therefore, it is necessary to develop strategies for model evaluation and justification, and to use them deliberately in group modeling practice.

For overcoming limited presence of Level 4, intervention by teachers will be needed when students do not realize the necessity of model evaluation or do not evaluate the explanatory nature of a model, such as processes or mechanisms of phenomena (Campbell et al. 2012). Since students tend to construct models with simple descriptions of phenomena, the teacher should help them experience the epistemology concerning evaluation and metacognitive awareness. Indeed, students with metacognitive awareness do not passively accept others' models, but take a critical view and reflect on their own reasoning processes as well as those of others. In our study, metacognition occurred during the process of checking self-understanding and monitoring others' understanding, and this involved the revision of others' incorrect conceptions. Both self-monitoring and peer monitoring could only happen when students took a critical view of others' opinions. Hence, teachers should encourage students to play an active role as listeners in group modeling practice, clearly describing the necessity of evaluating the model and developing the explanatory power of the model to the phenomena.

In terms of practical epistemology, we value the process that students used to construct models because it is the same process that scientists use to generate knowledge. We explored students' practical epistemologies in a science classroom and identified group modeling practice as a valuable aspect of science instruction at school. Furthermore, the purpose and evaluation criteria of models need to be explicitly provided for students in order to expand the modeling lessons and manage these lessons more effectively, as higher epistemological understanding will lead to an in-depth modeling process (Sins et al. 2009). Explicit epistemology lessons enable students to reflect on the nature of a given model and modeling (Schwarz and White 2005). Unfortunately, there are many practical limitations: for example, teachers' lack of understanding of model-based teaching and learning, limited class hours for the teaching of a large curriculum, school record-oriented teaching and learning, and a lack of awareness of the importance of the nature of science. To overcome these challenges, there is an urgent need to change the perceptions of curriculum developers, education administrators, teachers, students, and parents.

For further areas of research, the effect of individual epistemological beliefs on cognitive interaction in a group should be investigated. A student's epistemological belief or learning approach can influence learning processes and outcomes (Songer and Linn 1991). Thus, teachers needs to inquire into the beliefs of students before lessons are taught, and only engage in modeling practice after implementing proper actions. These endeavors would be helpful for understanding students' developmental practical epistemology in group modeling practice.

Acknowledgments This work was supported by the National Research Foundation of Korea Grant funded by the Korean Government (NRF-2012S1A5A2A03034667). The opinions expressed in this work are those of the authors and not necessarily those of the NRF.

Open Access This article is distributed under the terms of the Creative Commons Attribution License which permits any use, distribution, and reproduction in any medium, provided the original author(s) and the source are credited. 


\section{References}

Anderson, R. C., Nguyen-Jahiel, K., McNurlen, B., Archodidou, A., Kim, S., Reznitskaya, A., et al. (2001). The snowball phenomenon: Spread of ways of talking and ways of thinking across groups of children. Cognition and Instruction, 19(1), 1-46.

Arnaudin, M. W., \& Mintzes, J. J. (1985). Students' alternative conceptions of the human circulatory system: A cross-age study. Science Education, 69(5), 721-733.

Bamburger, Y. M., \& Davis, E. A. (2013). Middle-school science students' scientific modelling performances across content areas and within a learning progression. International Journal of Science Education, 35(2), 213-238.

Bell, T., Urhahne, D., Schanze, S., \& Ploetzner, R. (2010). Collaborative inquiry learning: Models, tools, and challenges. International Journal of Science Education, 32(3), 349-377.

Bianchini, J. A. (1997). Where knowledge construction, equity, and context intersect: Student learning of science in small groups. Journal of Research in Science Teaching, 34(10), 1039-1065.

Böttcher, F., \& Meisert, A. (2011). Argumentation in science education: A model-based framework. Science \& Education, 20(2), 103-140.

Buckley, B. C. (2000). Interactive multimedia and model-based learning in biology. International Journal of Science Education, 22(9), 895-935.

Buckley, B. C., \& Boulter, C. J. (1996). Investigating the role of representation and expressed models in building mental models. In J. K. Gilbert \& C. J. Boulter (Eds.), Developing models in science education (pp. 119-135). Dordrecht: Kluwer.

Buty, C., \& Mortimer, E. F. (2008). Dialogic/authoritative discourse and modeling in a high school teaching sequence on optics. International Journal of Science Education, 30(12), 1635-1660.

Campbell, T., Oh, P. S., \& Neilson, D. (2012). Discursive modes and their pedagogical functions in modelbased inquiry (MBI) classrooms. International Journal of Science Education, 34(15), 2393-2419.

Cartwright, N. (1999). The dappled world: A study of the boundaries of science. Cambridge: Cambridge University Press.

Champagne, A., Gunstone, R. F., \& Klopfer, L. E. (1983). Naive knowledge and science learning. Research in Science and Technological Education, 1(2), 173-183.

Cheng, M. F., \& Brown, D. E. (2010). Conceptual resources in self-developed explanatory models: The importance of integrating conscious and intuitive knowledge. International Journal of Science Education, 32(17), 2367-2392.

Chi, M. T. H. (2000). Self-explaining: The dual processes of generating inferences and repairing mental models. In R. Glaser (Ed.), Advances in instructional psychology (pp. 161-238). Mahwah, NJ: Lawrence Erlbaum Associates, Inc.

Chi, M. T. H. (2005). Commonsense conceptions of emergent processes: Why some misconceptions are robust. The Journal of the Learning Sciences, 14(2), 161-199.

Chi, M. T. H., Slotta, J. D., \& de Leeuw, N. (1994). Eliciting things to processes: A theory of conceptual change for learning science concepts. Learning and Instruction, 4(1), 27-43.

Chin, C., \& Osborne, J. (2008). Students' questions: A potential resource for teaching and learning science. Studies in Science Education, 44(1), 1-39.

Clement, J. J. (2000). Model based learning as a key research area for science education. International journal of Science Education, 22(9), 1041-1053.

Clement, J. J. (2008). Student/teacher co-construction of visualizable models in large group duscussion. In J. J. Clement \& M. A. Rea-Ramirez (Eds.), Model based learning and instruction in science (pp. 11-22). Dordrecht: Springer.

Doyle, J. K., \& Ford, D. N. (1998). Mental models concepts for system dynamics research. System Dynamics Review, 14(1), 3-29.

Dreyfus, A., Jungwirth, E., \& Eliovitch, R. (1990). Applying the "cognitive conflict" strategy for conceptual change-Some implications, difficulties, and problems. Science Education, 74(5), 555-569.

Gobert, J. D. (2000). A typology of causal models for plate tectonics: Inferential power and barriers to understanding. International Journal of Science Education, 22(9), 937-977.

Gobert, J. D., \& Buckley, B. (2000). Special issue editorial: Introduction to model-based teaching and learning. International Journal of Science Education, 22(9), 891-894.

Gobert, J. D., \& Pallant, A. (2004). Fostering students' epistemologies of models via authentic model-based tasks. Journal of Science Education and Technology, 13(1), 7-22.

Goos, M., Galbraith, P., \& Renshaw, P. (2002). Socially mediated metacognition: Creating collaborative zones of proximal development in small group problem solving. Educational Studies in Mathematics, 49(2), 193-223. 
Hofer, B. K., \& Pintrich, P. R. (1997). The development of epistemological theories: Beliefs about knowledge and knowing and their relation to learning. Review of Educational Research, 67(1), 88-140.

King, A. (1994). Guiding knowledge construction in the classroom: Effects of teaching children how to question and how to explain. American Educational Research Journal, 31(2), 338-368.

Krajcik, J., \& Merritt, J. (2012). Engaging students in scientific practices: What does constructing and revising models look like in the science classroom? Science Scope, 35(7), 6-8.

Kuhn, D. (1991). The skills of argument. Cambridge: Cambridge University Press.

Kyza, E. A., Constantinou, C. P., \& Spanoudis, G. (2011). Sixth graders' co-construction of explanations of a disturbance in an ecosystem: Exploring relationships between grouping, reflective scaffolding, and evidence-based explanations. International Journal of Science Education, 33(18), 2489-2525.

Lehrer, R., \& Schauble, L. (2012). Seeding evolutionary thinking by engaging children in modeling its foundations. Science Education, 96(4), 701-724.

National Research Council (NRC). (2000). Inquiry and the national science education standards. Washington, DC: National Academy Press.

Nelson, M. M., \& Davis, E. A. (2012). Preservice elementary teachers' evaluations of elementary students' scientific models: An aspect of pedagogical content knowledge for scientific modeling. International Journal of Science Education, 34(12), 1931-1959.

Nelson, T. O., \& Narens, L. (1994). Why investigate metacognition? In J. Metcalfe \& A. Shimamura (Eds.), Metacognition: Knowing about Knowing (pp. 1-26). Cambridge, MA: Bradford.

Núñez-Oveido, M. C., Clement, J., \& Rea-Ramirez, M. A. (2008). Developing complex mental models in biology through model evolution. In J. J. Clement \& M. A. Rea-Ramirez (Eds.), Model based learning and instruction in science (pp. 173-193). Dordrecht: Springer.

Oh, P. S., \& Oh, S. J. (2011). What teachers of science need to know about models: An overview. International Journal of Science Education, 33(8), 1109-1130.

Oversby, J. (2000). Models in explanations of chemistry: The case of acidity. In J. K. Gilbert \& C. J. Boulter (Eds.), Developing models in science education (pp. 227-251). Dordrecht: Kluwer.

Passmore, C. M., \& Stewart, J. (2002). A modeling approach to teaching evolutionary biology in high school. Journal of Research in Science Teaching, 39(3), 185-204.

Pelaez, N. J., Boyd, D. D., Rojas, J. B., \& Hoover, M. A. (2005). Prevalence of blood circulation misconceptions among prospective elementary teachers. Advances in Physiology Education, 29(3), $172-181$.

Rutherford, M. (2000). Models in the explanations of physics: The case of light. In J. K. Gilbert \& C. J. Boulter (Eds.), Developing models in science education (pp. 253-270). Dordrecht: Kluwer.

Sandoval, W. A. (2005). Understanding students' practical epistemologies and their influence on learning through inquiry. Science Education, 89(4), 634-656.

Sandoval, W. A., \& Reiser, B. J. (2004). Explanation-driven inquiry: Integration conceptual and epistemic scaffolds for scientific inquiry. Science Education, 88(3), 345-372.

Schraw, G., Crippen, K. J., \& Hartley, K. D. (2006). Promoting self-regulation in science education: Metacognition as part of a broader perspective on learning. Research in Science Education, 36(1-2), 111-139.

Schwarz, C. V., Reiser, B. J., Davis, E. A., Kenyon, L., Achér, A., Fortus, D., et al. (2009). Developing a learning progression for scientific modeling: Making scientific modeling accessible and meaningful for learners. Journal of Research in Science Teaching, 46(6), 632-654.

Schwarz, C. V., \& White, B. Y. (2005). Metamodeling knowledge: Developing students' understanding of scientific modeling. Cognition and Instruction, 23(2), 165-205.

Sins, P. H. M., Savelsbergh, E. R., van Joolingen, W. R., \& van Hout-Wolters, B. H. A. M. (2009). The relation between students' epistemological understanding of computer models and their cognitive processing on a modeling task. International Journal of Science Education, 31(9), 1205-1229.

Songer, N. B., \& Linn, M. C. (1991). How do students' views of science influence knowledge integration? Journal of Research in Science Teaching, 28, 761-784.

Svoboda, J., \& Passmore, C. (2013). The strategies of modeling in biology education. Science \& Education, 22(1), 119-142.

Verhoeff, R. P., Waarlo, A. J., \& Boersma, K. T. (2008). Systems modeling and the development of coherent understanding of cell biology. International Journal of Science Education, 30(4), 543-568.

Wertsch, J. V. (1991). Voices of the mind: A sociocultural approach to mediated action. Cambridge, MA: Harvard University Press.

Windschitl, M., Thompson, J., \& Braaten, M. (2008). Beyond the scientific method: Model-based inquiry as a new paradigm of preference for school science investigations. Science Education, 92(5), 941-967.

Yip, D. Y. (1998). Identification of misconceptions in novice biology teachers and remedial strategies for improving biology learning. International Journal of Science Education, 20(4), 461-477. 